\title{
Sero-epidemiology study of leptospirosis in febrile patients from Terai region of Nepal
}

\author{
Lalmani Regmi ${ }^{1,2}$, Kishor Pandey ${ }^{2,3^{*}}$, Meena Malla ${ }^{2}$, Santosh Khanal ${ }^{1}$ and Basu Dev Pandey ${ }^{4}$
}

\begin{abstract}
Background: Leptospirosis is a re-emerging zoonotic disease caused by pathogenic strains of bacteria belonging to genus Leptospira whose symptoms can range from mild clinical manifestations to a severe life threatening illness. This disease may be under-recognized in resource poor settings like Nepal where many clinical laboratories lack appropriate equipment, technology and personnel for proper diagnosis.

Methods: We used IgM ELISA to estimate the sero-prevalence of leptospirosis in a group of febrile patients in a western region of Nepal. We also tested for possible co-infection with two other common febrile diseases endemic to Nepal including dengue and typhoid fever.

Results: Among samples from 144 febrile patients, 30 (21\%) were positive for leptospiral IgM. In univariate analysis, leptospirosis was significantly associated with being of working age $(p=0.019)$, farming $(p=0.045)$ and water and animal contact $(p=0.0001)$. Widal and dengue serological study showed that the majority of leptospirosis infections did not have an alternative diagnosis.

Conclusion: As indicated by the study, regular surveillance of animal reservoirs in collaboration with veterinary department and inclusion of leptospirosis as a differential diagnosis of febrile illness is thus recommended based on the current findings.
\end{abstract}

Keywords: ELISA, Leptospira, Nepal

\section{Background}

Leptospirosis is a zoonotic disease which occurs in diverse epidemiological conditions. It mainly affects vulnerable populations including farmers from rural areas and slum dwellers from urban areas [1]. The outcome of the disease ranges from an undifferentiated febrile illness to lifethreatening manifestations such as Weil's disease and severe pulmonary haemorrhage syndrome. The severe forms of the disease cause mortality in about $5-40 \%$ [2]. Therefore, prompt diagnosis and early administration of appropriate antibiotics are important [2]. A recent study estimated that there are annually 1.03 million cases (95\% CI 434,000$1,750,000)$ and 58,900 deaths (95\% CI 23,800-95,900) due to leptospirosis worldwide [1]. The estimated 1.03 million cases annually result in a total of approximately 2.90 million Disability Adjusted Life Years (DALY) [3]. Pathogenic

\footnotetext{
* Correspondence: pandey kishor@hotmail.com

${ }^{2}$ Everest International Clinic and Research Center, Kathmandu, Nepal

${ }^{3}$ Unit of Molecular Biotechnology, Nepal Academy of Science and

Technology (NAST), Khumaltar, Lalitpur, Nepal

Full list of author information is available at the end of the article
}

Leptospira are wide spread and they are capable of surviving in both environment and renal tubule of the animals that get infected [4]. Infection occurs during exposure to animal reservoirs or an environment contaminated by their urine [2]. Many wild and domestic animals are potential reservoirs of the causative spirochetes [5]. These include rodents (especially rats), dogs, cattle, pigs, and horses [6].

Leptospirosis is difficult to diagnose because of its non-specific symptoms, clinical resemblance to other common disorders, and multi-organ involvement [7]. Antibodies are detectable in the blood approximately 5 to 7 days after the onset of symptoms and most cases of leptospirosis are diagnosed by serology [8]. Most commonly used serological tests are Microscopic Agglutination Test (MAT) and ELISA [9]. MAT, however, is slow, tedious, potentially bio-hazardous, subjective and painstaking, requiring the meticulous curating of a collection of strains used alive as antigens [10] and thus is restricted to laboratories that are capable for maintaining strains for preparation of live antigens [11]. The 
immunoglobulin $M$ (IgM) enzyme-linked immunosorbent assay (ELISA) is one of the alternatives to MAT [12]. ELISA is not serovar specific but is an excellent choice in screening and surveillance [10].

There is a high prevalence of leptospirosis in Asian countries. Frequent outbreaks occur in developing countries related to overcrowding, poor sanitation, and climactic condition [13]. Epidemics of leptospirosis have been reported in Sri Lanka in 2008 and the Philippines in 2009 [14]. Most cases reported from India are from the four states of Kerala, Gujarat, Tamil Nadu and Maharashtra $[15,16]$. The first report of a suspected leptospiral infection in Nepal was in a Nepali soldier in 1981 [17]. Since then, a number of serological studies have been carried out in Nepal, showing the presence of antibodies against Leptospira in a number of populations [18-21]. Leptospirosis is an under diagnosed disease in Nepal and easily mistaken for other febrile illnesses. This study was undertaken to evaluate the seroprevalence of leptospirosis in the Terai region of Nepal and recommend the health practitioners to consider the disease in differential diagnosis of febrile illness.

\section{Methods}

\section{Study population}

A total of 144 febrile patients who visited a government hospital (Rapti Zonal Hospital) and three private clinics
(Dirghayu Polyclinic, Palpali Polyclinic and Kamana Pharmacy) in Dang, Western part of Nepal were included in the present study (Fig. 1). The study was carried out in the monsoon period of June-August 2014. A blood sample was collected from all febrile patients at the time of their hospital/clinics visit. We collected blood samples from the febrile patients who had fever at least 3 days. We excluded the patients' with fever for less than 3 days. Serum samples exhibiting haemolysis, lipaemia or microbial growth were also excluded from the study [22]. Samples were centrifuged, stored, and shipped at $4{ }^{\circ} \mathrm{C}$ to the Everest International Clinic and Research Centre, Kathmandu. A standardized questionnaire was used to collect patients information regarding demographic details (age, sex, and occupation), clinical symptoms (fever, headache, myalgia, vomiting, diarrhea, and abdominal pain), animal or water contact, and presence of pets at home.

\section{Serological study}

Detection of IgM antibodies to Leptospira was determined using a commercially available Leptospira IgM capture using a microtiter plate ELISA (Panbio Leptospira IgM ELISA, Queensland, Australia). The ELISA test was performed according to the manufacturer's protocol and interpreted either positive or negative on the basis of absorbance with respect to cutoff values. The

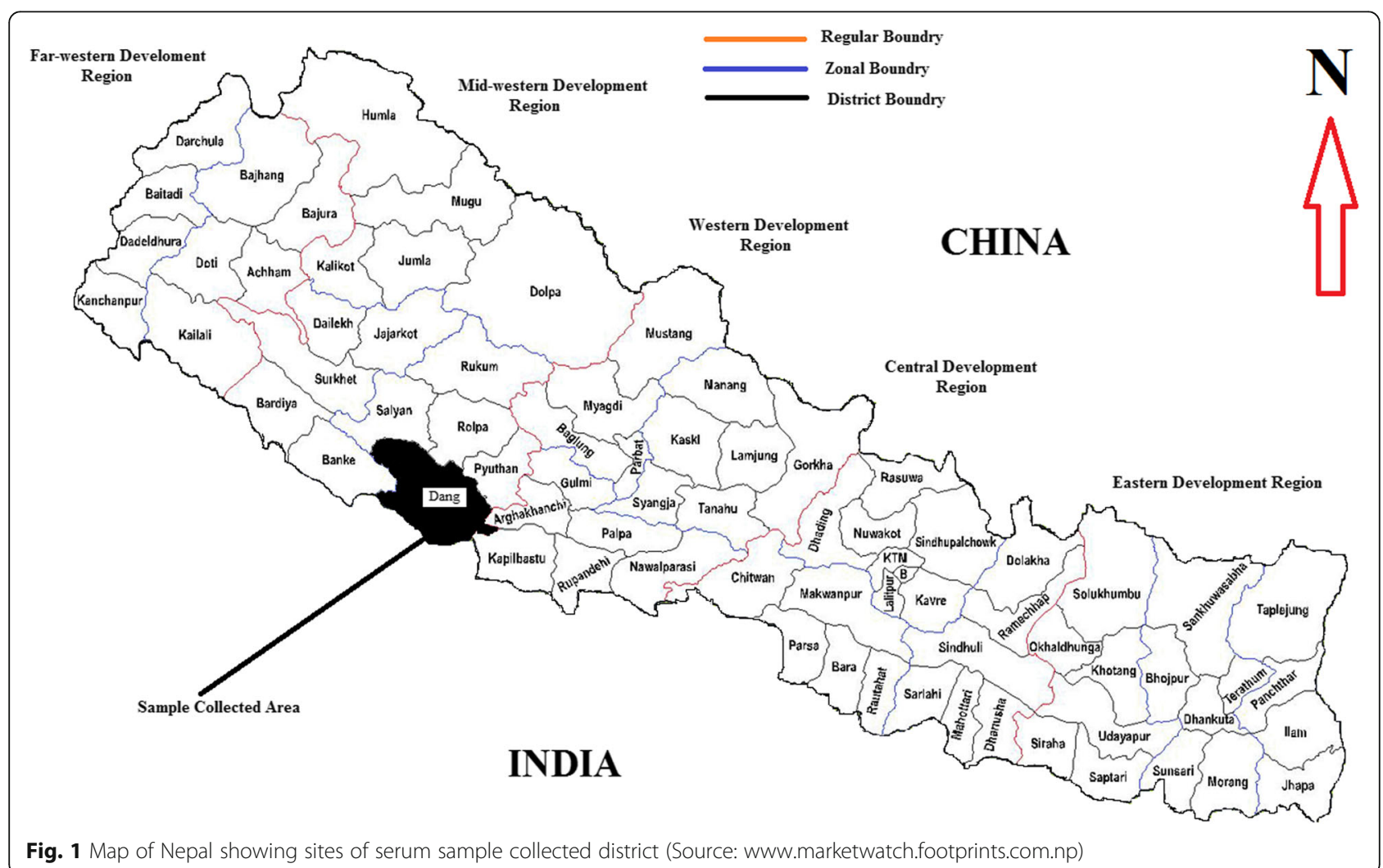

Fig. 1 Map of Nepal showing sites of serum sample collected district (Source: www.marketwatch.footprints.com.np) 
sensitivity and specificity of the ELISA kits were 96.5\% $(95 \% \mathrm{CI}=87.9-99.6 \%)$ and $98.5 \%(95 \% \mathrm{CI}=95.6-$ 99.7\%). A sample was considered "Positive" if Panbio units calculated for it is more than $11 \mathrm{IU} / \mathrm{mL}$. A sample was considered "Equivocal" if Panbio units calculated for it is $9-11 \mathrm{IU} / \mathrm{mL}$. A sample was considered "Negative" if Panbio units calculated for it is less than $9 \mathrm{IU} / \mathrm{mL}$. Briefly, test sera, cutoff calibrator, and positive and negative control sera were diluted 1:100 in serum diluents, and $100 \mu \mathrm{L}$ added to Leptospira antigen-coated microwells and incubated for $30 \mathrm{~min}$ at $37{ }^{\circ} \mathrm{C}$. After washing with phosphate-buffered saline containing $0.05 \%$ Tween 20, $100 \mu \mathrm{L}$ of HRP conjugated anti-human IgM was added and incubated for another $30 \mathrm{~min}$ at $37{ }^{\circ} \mathrm{C}$. After further washing, $100 \mu \mathrm{L}$ of tetramethylbenzidine substrate was added and incubated at room temperature for $10 \mathrm{~min}$, after which the reaction was stopped with $100 \mu \mathrm{L}$ of $1 \mathrm{M}$ phosphoric acid. The absorbance of each well was read at a wavelength of $450 \mathrm{~nm}$ with a Bio-Tek ELX 808 plate reader (Bio-Tek Instruments, Winooski, VT). The widal test was performed to detect antibodies against $\mathrm{O}$ and $\mathrm{H}$ antigens. The samples which showed agglutination with the antigenic reagents were considered positive and those that do not agglutinate were considered negative. Detection of anti-dengue IgM by ELISA was performed using SD dengue IgM capture ELISA (Standard Diagnostics Inc.) according to the manufacturer's instructions.

\section{Statistical methods}

Statistical package for social science (SPSS) software (version 17.0) was used for data entry and analysis. Association of different variables to leptospirosis was analyzed by using Chi-square test and $p<0.05$ was considered significant.

\section{Results}

Most of the patients were adults with a mean age of 31.75 years. The majority of Leptospira IgM positive cases $(43.3 \%)$ were from the $31-40$ years age group followed by the $21-30$ years age groups with $29.3 \%$ positive for leptospirosis. The youngest age showing positive result was 12 years and the oldest age was 58 years. Among the Leptospira IgM positives, most were adults with mean age of 28.3 years. Statistically there was significant association in the presence of leptospirosis among various age groups $(p=0.019)$ (Table 1). The male and female ratio is 1: 1.1. Out of 68 females, 17 (25.0\%) were found to be serologically positive. Similarly, 13 (17.1\%) out of 76 males were found to be serologically positive for leptospirosis. Statistically there was no significant difference in the presence of leptospirosis among sexes $(p=0.244)$ (Table 1$)$.

Of the 22 cases having animal contact, $13.6 \%$ were positive for IgM against Leptospira species. Similarly of
Table 1 Demographic presentation of leptospirosis

\begin{tabular}{llll}
\hline Age of patients & \multicolumn{2}{l}{ ELISA for febrile patients } & P-value \\
\cline { 2 - 3 } & Positive (\%) & Negative (\%) & \\
\hline$<10$ & $0(0.0 \%)$ & $9(6.3 \%)$ & 0.019 \\
$11-20$ & $6(4.2 \%)$ & $24(16.7 \%)$ & \\
$21-30$ & $12(9.0 \%)$ & $29(20.1 \%)$ & \\
$31-40$ & $10(6.3 \%)$ & $15(10.4 \%)$ & \\
$41-50$ & $0(0.0 \%)$ & $15(10.4 \%)$ & \\
$51-60$ & $2(1.4 \%)$ & $11(7.6 \%)$ & \\
$61-70$ & $0(0.0 \%)$ & $9(6.3 \%)$ & 0.244 \\
$>70$ & $0(0.0 \%)$ & $2(1.4 \%)$ & \\
Gender & & & \\
Male & $13(9.0 \%)$ & $63(43.8 \%)$ & \\
Female & $17(11.8 \%)$ & $51(35.4 \%)$ & \\
Total & $30(20.8 \%)$ & $114(79.2 \%)$ & \\
\hline
\end{tabular}

the 32 cases having water contact, $43.8 \%$ were IgM positives against Leptospira. Among the cases having animal and water contact, $39.1 \%$ were positive for IgM ELISA. Of the cases that had animal or water contact, $5.9 \%$ were positive for leptospirosis by ELISA. Statistically significant association was found between animal/water contact pattern and leptospirosis infection $(p=0.0001)$ (Table 2).

The most common clinical symptoms shown by the 144 patients were fever (100\%), headache (69.4\%), Myalgia (55.4\%), vomiting (13.9\%), diarrhea (13.9\%), abdominal pain $(13.9 \%)$ and Jaundice $(8.3 \%)$ as shown in Table 3. Patients were subjected to routine laboratory checks, including white blood cells (WBCs), platelets, and hemoglobin $(\mathrm{Hb})$ levels. Out of 144 serum samples from patients suspected of leptospirosis, 30 (20.83\%) were positive for anti-Leptospira IgM antibody. Clinical sign and symptoms of the 30 ELISA positive cases of leptospirosis were further analyzed. Fever, headache and myalgia were the most common symptoms of ELISA positive cases. The present study also revealed leptospirosis to be most common among farmers (26.7\%), followed by students (23.3\%), masons (20\%), housewives (13.3\%), servicemen (10\%) and businessmen (6.7\%). Of

Table 2 Risk factor association with leptospirosis

\begin{tabular}{llll}
\hline Risk factors & \multicolumn{2}{l}{ ELISA for febrile patients } & P-value \\
\cline { 2 - 3 } & Positive (\%) & Negative (\%) & \\
\hline Animal contact & $3(2.1 \%)$ & $19(13.2 \%)$ & 0.001 \\
Water contact & $14(9.7 \%)$ & $18(12.5 \%)$ & \\
Both & $9(6.3 \%)$ & $14(9.7 \%)$ & \\
Other & $4(2.8 \%)$ & $63(43.8 \%)$ & \\
Total & $30(20.8 \%)$ & $114(79.2 \%)$ & \\
\hline
\end{tabular}


Table 3 Clinical presentation of the patients visited to hospital/ clinics

\begin{tabular}{lll}
\hline $\begin{array}{l}\text { Clinical Sign/ } \\
\text { Symptoms }\end{array}$ & $\begin{array}{l}\text { No. of cases showing } \\
\text { symptoms (\%) }\end{array}$ & $\begin{array}{l}\text { Percentage of ELISA } \\
\text { positive cases (\%) }\end{array}$ \\
\hline Fever & $144(100)$ & $30(100)$ \\
Headache & $100(69.4)$ & $23(76.3)$ \\
Myalgia & $80(55.4)$ & $21(70.1)$ \\
Vomiting & $20(13.9)$ & $9(30.5)$ \\
Diarrhoea & $20(13.9)$ & $8(26.4)$ \\
Abdominal pain & $20(13.9)$ & $5(16.7)$ \\
Jaundice & $12(8.3)$ & $4(13.9)$ \\
& Value & \\
Hb, g/dL $(N=144)$ & \\
Median & 12.5 & \\
Minimum & 7.5 & \\
Maximum & 19.8 & \\
WBC, per $\mu \mathrm{L}(\mathrm{N}=144)$ & \\
Median & 8500 & \\
Minimum & 1100 & \\
Maximum & 32,400 & \\
Platelets, per $\mu \mathrm{L}(\mathrm{N}=144)$ & 176,000 & \\
Median & 16,500 & \\
Minimum & $4,000,001$ & \\
Maximum & & \\
\hline
\end{tabular}

the 30 sero-positive patients, two were involved in business and three in the service sector (data not shown).

Only one of the patient's positive for leptospiral IgM ELISA was also positive for the Widal. Similarly, only one patient positive for leptospiral IgM ELISA also tested positive for dengue IgM.

\section{Discussion}

We show that a large proportion (21\%) of febrile patients presenting to a Nepali hospital/clinics during summer season had serologic evidence of acute leptospirosis. A study conducted at Chitwan Medical College across 1266 patients suspected of leptospirosis revealed sero-positivity in $61(4.8 \%)$ cases [21]. When restricted to analysis of patients presenting during the summer, their sero-positivity rate was $21.3 \%$, which is in line with our findings.

Most of the sero-positive cases were within the 21-30 and 31-40 age groups. The clustering of the disease in these age groups is consistent with occupational exposures in these "working" ages. In the study carried out by Seti et al., [23] most of the patients (70\%) positive for leptospirosis were young adults in their 2nd, 3rd or 4th decades of life. Similarly, in another study done by Chawla et al. [24], the highest percentage of positive for leptospirosis cases were from the middle age group. We found a higher incidence of leptospirosis among females that was not statistically significant, in contrast with previous studies demonstrating higher incidence of leptospirosis in males [23-26]. The higher incidence in females at our site may be due to emigration of males to foreign countries for work, resulting in an increase in female participation in farming and other work previously dominated by males.

Of the cases having animal contact (cattle, buffaloes and pets), $26.6 \%$ were seropositive. Rearing cows and/or buffaloes is a common practice in Nepal, and these animals are often chronically colonized by pathogenic Leptospira with frequent transmission to humans [27]. The Directorate of Animal Health, Nepal reported an overall 10.5\% incidence of leptospirosis in cattle and buffalo, goat, sheep and pig. Dogs have become popular pets with a risk of Leptospira transmission [28]. In a study conducted in 150 dogs presenting with fever and jaundice, serological positivity for leptospirosis was established in 2.7\% (4/150) of those [29]. Similarly, of the cases having water contact, $41.8 \%$ were ELISA positive. The study period coincides with the paddy growing season in Nepal, and an increase in leptospirosis has been associated with the rice paddy harvesting season where an increase in the rodent population in and around the field is observed [26]. Swimming in pools or white water rafting as a recreational activity is becoming popular in urban areas of Nepal too. Numerous studies have shown that such activities have been associated with leptospirosis [30, 31].

Leptospirosis has traditionally been considered a disease of farmers $[29,30]$. In accordance to these findings, the present study also revealed to be most common among farmers, followed by students, masons, housewives, servicemen and businessmen. Their profession didn't carry any risk for leptospirosis and seems like they might have acquired it by accidental animal/water contact.

One of the patients who tested sero-positive for leptospirosis also tested positive for Widal test. Clinical manifestations did not hint at the worsening of clinical symptoms of the patient, as expected for the coinfections. Blood samples from the patient in the first week of fever was not available for culture to trace the microbial etiology of the Widal positivity (convalescence samples were also not available). Since this test is nonspecific, positive results may also indicate the cross reactivity with antibodies specific to bacterial (members of enterobacteriaceae) and non-bacterial (malaria, dengue, hepatitis $\mathrm{A}$, and infectious mononucleosis) diseases and may have previous infection [32].

$1 / 144$ samples also showed seropositivity for both leptospirosis and dengue specific IgM. The positive IgM result for dengue could be considered an old infection. The IgM antibodies for dengue generally remain in circulation for prolonged periods of time. Clinical presentation of dengue fever and leptospirosis are considerably overlapping, 
leading to misdiagnosis in cases of mixed infection. In acute stage of infection, both present as acute febrile illness with chills, myalgia, headache, abdominal pain, and anorexia. Though dengue IgM can persist for months, the severity of the observed symptoms in the patient suggested that it could more likely be a simultaneous infection of dengue and leptospira. This patient also presented arthalgia in addition to non-specific symptoms of leptospirosis, inferring the symptomatic aggravation by the coinfection. Such co-infections have been previously reported in Nepal and India [33, 34].

This study has several limitations, the greatest of which is its cross-sectional nature, as we were not able to collected paired serum samples. Secondly, we only collected samples over a short duration, though we chose the summer season as it has the highest incidence of disease. Thirdly, MAT, the gold standard test for leptospirosis could not be done, nor we could perform blood culture or any molecular tests. However, we believe that the result of this study describes the general features of the disease in Nepal.

\section{Conclusion}

This study indicates Leptospirosis is a significant public health problem in Nepal. In resource poor countries like Nepal where laboratories performing MAT or maintaining cultures are rarely available, serological test like ELISA could well depict the scenario of the disease prevalence. This study highlights urgency of comprehensive investigation in coordination with animal health department as a one of the health approaches to find the situation of leptospirosis in Nepal and accordingly to formulate reflect in policy for control of disease.

\section{Abbreviations}

DALY: Disability adjusted life years; ELISA: Enzyme-linked immunosorbent assay; IgM: Immunoglobulin M; MAT: Microscopic agglutination test

\section{Acknowledgements}

We thank Daniel Leung, University of Utah School of Medicine, US for critically reading this manuscript. We are thankful to the staff of Everest International Clinic and Research Center, Kathmandu for their technical help. We are extremely grateful to the Medical Superintendents, doctors, nurses, laboratory staff, and patients of the respective hospitals and clinics for their kind support during the study. We would also like to thank all the people for their assistance in sample collections.

\section{Funding}

Not applicable

\section{Availability of data and materials}

The data sets analyzed during the current study is available from the authors Lalmani Regmi and Kishor Pandey on reasonable request.

\section{Authors' contributions}

$L R, K P, B D P$ conceived the study; LR, KP, SK designed the study protocol; $L R$, BDP carried out the clinical assessment; $L R, M M, K P$ carried out the experiment and interpretation of data. LR, KP, BDP drafted the manuscript. $L R, S K, B D P$ are guarantors of the papers. All authors read and approved the final manuscript.

\section{Competing interest}

The authors declare that they have no competing interests.

Ethics approval and consent to participate

The demographic data used in this study were obtained from medical records of the hospital and clinic. The clinical specimens were received for routine diagnostic process and do not require ethical approval since the process is for the management of patients as indicated by National guidelines. Permission to conduct the study was obtained from the participating hospital and private clinic.

\section{Consent for publication}

Not applicable.

\section{Publisher's Note}

Springer Nature remains neutral with regard to jurisdictional claims in published maps and institutional affiliations.

\section{Author details}

${ }^{1}$ National College, Kathmandu, Nepal. ${ }^{2}$ Everest International Clinic and Research Center, Kathmandu, Nepal. ${ }^{3}$ Unit of Molecular Biotechnology, Nepal Academy of Science and Technology (NAST), Khumaltar, Lalitpur, Nepal. ${ }^{4}$ Department of Health Services, Ministry of Health, Government of Nepal, Kathmandu, Nepal.

Received: 16 June 2017 Accepted: 12 September 2017

Published online: 18 September 2017

\section{References}

1. Costa F, Hagan JE, Calcagno J, Kane M, et al. Global morbidity and mortality of Leptospirosis: a systematic review. PLoS Negl Trop Dis. 2015;9:e0003898.

2. Croda J, Ramos JGR, Matsunaga J, et al. Leptospira immunoglobulin-like proteins as a serodiagnostic marker for acute leptospirosis. J Clin Microbiol. 2007;5:1528-34

3. Torgerson PR, Hagan JE, Costa F, et al. Global burden of Leptospirosis: estimated in terms of disability adjusted life years. PLoS Negl Trop Dis. 2015:9:e0004122.

4. Shang ES, Exner MM, Summers TA, et al. The rare outer membrane protein, OmpL1, of pathogenic Leptospira species is a heat-modifiable porin. Infect Immun. 1995;63:3174-81.

5. Tangkanakul W, Tharmaphornpil P, Plikaytis BD, et al. Risk factors associated with Leptospirosis in northeastern Thailand, 1998. Am J Trop Med Hyg. 2000;63(3-4):204-48.

6. Laurichesse H, Gourdon F, Smits HL, et al. Safety and immunogenicity of subcutaneous or intramascular administration of a monovalent inactivated vaccine against Leptospira interrogans serogroup icterohaemorrhagiae in healthy volunteers. Clin Microbial Infect. 2007;13:395-403.

7. Rajapakse S, Weeratunga P, Niloofa R, et al. A Diagnostic scoring model for leptospirosis in resource limited settings. PLoS Negl Trop Dis. 2016; 10(6):e0004513.

8. Levett PN, Branch SL, Whittington CU, et al. Two methods for rapid serological diagnosis of acute Leptospirosis. Clin Diagn Lab Immunol. 2001;8:349-51.

9. Oliveira TR, Longhi MT, de Morais ZM, et al. Evaluation of leptospiral recombinant antigens MPL17 and MPL21 for serological diagnosis of Leptospirosis by enzyme-linked immnosorbent assays. Clin Vaccine Immunol. 2008;15:1715-22

10. Faine S. Leptospira. In Topley and Wilson's Microbiology and Microbial Infections, Collier L and Max A. Vol 2, $9^{\text {th }}$ edition. London: Arnold. 1998. p. 1287-1304.

11. Gussenhoven GC, Mawgvd H, Goris MGA, et al. LEPTO dipstick, a dipstick assay for detection of Leptospira-specific immunoglobulin $M$ antibodies in human sera. J Clin Microbiol. 1996;35:92-7.

12. Bajani MD, Ashford DA, Bragg SL. Evaluation of four commercially available rapid serological tests for diagnosis of leptospirosis. J Clin Microbiol. 2003:41:803-9.

13. Victoriano AFB, Smythe LD, Gloriani-Barzaga N, et al. Leptospirosis in the Asia Pacific region. BMC Infect Dis. 2009;9:147.

14. Hartskeerl RA, Collares-Pereira M, Ellis WA. Emergence, control and reemerging leptospirosis: dynamics of infection in the changing world. Clin Microbiol Infect. 2011;17:494-501. 
15. Shivakumar S. Leptospirosis current scenario in India. API Med Update. 2008;18:799-809.

16. World Health Organization. Report of the brainstorming meeting on Leptospirosis prevention and control. New Delhi: Indian Council of Medical Research; 2006.

17. Brown GW, Madasamy M, Bernthal P. Groves MG Leptospirosis in Nepal. Trans R Soc Trop Med Hyg. 1981;75(4):572-3.

18. Rai SK, Shibata H, Uga S, et al. Serologial study of Leptospira infection by one-point MCA method. J Infect Dis Antimicrob Agents. 2000;17:29-32.

19. Murdoch DR, Woods CW, Zimmerman MD, et al. The etiology of febrile illness in adults presenting to Patan Hospital in Kathmandu, Nepal. Am J Trop Med Hyg. 2004;70:670-5.

20. Myint KS, Murray CK, Scott RM, et al. Incidence of leptospirosis in a select population in Nepal. Trans R Soc Trop Med Hyg. 2010;104(8):551-5.

21. Nepal HP, Acharya A, Gautam R, et al. Serological study of Leptospirosis in central Nepal. Int J of Biomed Adv Res. 2013;4:455-9.

22. World Health Organization. Human Leptospirosis: guidance for diagnosis surveillance and control. World Health organization, Malta. 2003.

23. Sethi S, Sharma N, Kakkar N, et al. Increasing trends of Leptospirosis in northern India: a clinoco-epidemiological study. PLoS Negl Trop Dis. 2010;4: e579. https://doi.org/10.1371/journal.pntd.0000579.

24. Chawla V, Tridevi TH, Yeolekar ME. Epidemic of Leptospirosis: an ICU experience. J Assoc Physicians India. 2004;52:619-22.

25. Forster KM, Hartwig DD, Seixas FK, et al. Characterization of a virulent Leptospira interrogans strain isolated from an abandoned swimmingpool. Braz J Microbiol. 2013:44(1):165-70.

26. Panaphut T, Domrongkitchaiporn S, Thinkamrop B. Prognostic factors of death in Leptospirosis: a prospective cohort study in Khon Kaen Thailand. Int J Infect Dis. 2002;6:52-9.

27. Chandrasekaran S, Pankajalakshmi V. Usefulness of dark field microscopy after differential centrifugation in the early diagnosis of Leptospirosis in dog and its human contacts. Indian J Med Sci. 1997;51:1-4.

28. Thakur M. Sero-prevalence of leptospiral infection in canine population of Kathmandu valley. Nepal J Agric Sci. 2014;12:67-73.

29. Haake DA, Dundoo M, Cader R, et al. Leptospirosis, water sports and chemoprophylaxis. Clin Infect Dis. 2002;34:40-3.

30. Castellanos CBL, Suarez RG, Figueroa EG, et al. Risk factors and the prevalence of Leptospirosis infection in a rural community of Chipas, Mexico. Epidemiol Infect. 2003:131:1149-56.

31. Agampodi SB, Dahanayaka NJ, Bandaranayaka AK, et al. Regional differences of leptospirosis in Sri Lanka: observations from a flood-associated outbreak in 2011. PLoS Negl Trop Dis. 2014;8:e2626.

32. Ley B, Mtove G, Thriemer K, et al. Evaluation of the Widal tube agglutination test for the diagnosis of typhoid fever among children admitted to a rural hdospital in Tanzania and a comparison with previous studies. BMC Infect Dis. 2010; https://doi.org/10.1186/1471-2334-10-180.

33. Kumar A, Balachandran V, Dominic A, et al. Serological evidence of leptospirosis and dengue coinfection in an endemic region in South India. Annal Trop Med Pub Health. 2012;5:286-90.

34. Mishra B, Singhal L, Sethi S, et al. Leptospirosis coexistent with dengue fever: a diagnostic dilemma. J Glob Infect. 2013;5:121-2.

\section{Submit your next manuscript to BioMed Central and we will help you at every step:}

- We accept pre-submission inquiries

- Our selector tool helps you to find the most relevant journal

- We provide round the clock customer support

- Convenient online submission

- Thorough peer review

- Inclusion in PubMed and all major indexing services

- Maximum visibility for your research

Submit your manuscript at www.biomedcentral.com/submit
Biomed Central 